\title{
Giải pháp thúc đẩy chuyển đổi sản xuất lúa theo hướng hữu cơ tại Đồng bằng sông Cửu Long: Nghiên cứu trường hợp tỉnh Vĩnh Long và các ngụ ý chính sách
}

\section{Recommendations to convert from conventional to organic rice production in the Mekong Delta: Vinh Long province case study and policy implications}

\author{
Khổng Tiến Dũng ${ }^{1 *}$ \\ ${ }^{1}$ Trường Đại học Cần Thơ, Việt Nam \\ "Tác giả liên hệ, Email: ktdung@ctu.edu.vn
}

THÔNG TIN

DOI: $10.46223 / \mathrm{HCMCOUJS}$. econ.vi.17.1.61.2022

Ngày nhận: 11/03/2020

Ngày nhận lại: 30/03/2020

Duyệt đăng: 20/04/2020

Tù khóa:

chuyển đổi; hiệu quả tài chính; lúa hữu cơ; Vĩnh Long

Keywords:

conversion; financial efficiency; organic rice; Vinh Long
TÓM TẮT

Nghiên cứu này phân tích thực trạng sản xuất và tính toán hiệu quả tài chính của mô hình sản xuất lúa thông thường và mô hình lúa theo hướng hữu cơ tại tỉnh Vĩnh Long. Nghiên cứu sử dụng hàm lợi nhuận biên ngẫu nhiên Cobb-Douglas theo phương pháp ước lượng hợp lý cực đại (Maximum Likelihood Estimation - MLE) nhằm tìm hiểu các nhân tố tác động đến lợi nhuận chuẩn hóa của mô hình sản xuất lúa. Ngoài ra, mô hình nhị phân Logistic cũng xác định các yếu tố ảnh hưởng đến quyết định chuyển đổi từ mô hình truyền thống sang mô hình hữu cơ. Kết quả phân tích xác định mặc dù còn nhiều khó khăn như công lao động cao và chi phí sử dụng phân sinh học chiếm gần $50 \%$ trong cơ cấu chi phí, mô hình hữu cơ vẫn có lợi nhuận khoảng 1.4 triệu đồng/ $1,000 \mathrm{~m}^{2}$ tương đương mô hình truyền thống do giá bán cao và được bao tiêu sản phẩm. Mô hình phân tích xác định được các hộ có diện tích sản xuất lớn mong muốn chuyển sang mô hình hữu cơ, trong khi tuổi chủ hộ và những hộ có thu nhập từ các nguồn khác ngoài lúa là rào cản chính để nông hộ chuyển đổi.

\section{ABSTRACT}

This study aims to analyse the current production situation and estimate the financial efficiency of conventional and organic rice production in Vinh Long province. The Cobb-Douglas random profit margin function using the Maximum Likelihood Estimation (MLE) was employed to identify the determinants affecting the standardized profitability of the rice production using. Besides, the Binary Logistic model also identifies factors that influence the decision to convert from traditional to organic rice production. The results find that, although there are some challenges such as high labor cost and high spending for biological fertilizer accounting about $50 \%$ of the total cost, the organic production still achieve about 1.4 million $\mathrm{VND} / 1,000 \mathrm{~m}^{2}$ which is equivalent to traditional rice production because of the 
high selling price and consumption contract. This research also reveals that households with large production areas intend to convert to organic production, while household head age and those with incomes from other sources are the main barriers for farmers to switch to organic rice production.

\section{Giới thiệu}

Đồng Bằng Sông Cửu Long (ĐBSCL) được xem là đơn vị đi đầu về xuất khẩu lúa gạo, trái cây và thủy sản của cả nước. Mỗi năm, khu vực này xuất khẩu hơn $90 \%$ lượng gạo của cả nước, tương ứng với hơn $20 \%$ thị phần toàn cầu. Lượng xuất khẩu này mang lại kim ngạch khoảng 02 tỷ USD cho Việt Nam. Tính đến tháng 04/2017, ĐBSCL đóng góp 54\% sản lượng lúa, $70 \%$ sản lượng thủy sản nuôi trồng, và 36.5\% lượng trái cây cả nước (Cổng thông tin điện tử Vĩnh Long, 2018). Song song với những thành tựu đó, ngành hàng này hiện nay vẫn đang gặp phải những khó khăn trong sản xuất như: quy mô sản xuất đơn lẻ, phương thức canh tác lạc hậu, năng lực sản xuất yếu kém, năng suất thấp và giá thành chưa ổn định (Vo \& Nguyen, 2011), nhất là tình trạng ô nhiễm môi trường do sử dụng quá mức thuốc bảo vệ thực vật và phân bón. Do đó, việc định hướng sản xuất lúa gạo theo qui chuẩn về chất lượng, giảm chi phí đầu tư phân hóa học, thuốc bảo vệ thực vật để nâng cao giá trị ngành hàng và đảm bảo sử dụng bền vững nguồn lực sản xuất là cần thiết. Sự chuyển đổi từ canh tác lúa gạo truyền thống sang canh tác lúa gạo hữu cơ được phát động trong thời gian gần đây sẽ là một trong những giải pháp đáp ứng cho định hướng trên (T. V. Nguyen et al., 2020). Ngoài ra, nhu cầu của người tiêu dùng gạo hiện nay đối với sản phẩm sạch và chất lượng ngày càng cao do mức sống cải thiện, nhất là ở khu vực thành thị. Điều này dẫn tới nhu cầu về gạo hữu cơ tăng lên. Theo đề án tái cơ cấu ngành hàng lúa gạo, trong năm 2017, Bộ Nông nghiệp và Phát triển nông thôn đã giao cho Cục trồng trọt tiến hành xây dựng và hoàn thành đề án vùng sản xuất lúa theo quy trình GAP và hữu cơ, giảm phát thải khí nhà kính (Bộ Nông nghiệp và phát triển nông thôn, 2016). Theo đó, vào năm 2025 diện tích lúa hữu cơ gieo trồng phải đạt từ 50,000 đến 70,000 ha và phải đạt khoảng từ 100,000 đến 150,000 ha vào năm 2030 . Như vậy, việc đẩy mạnh phát triển lúa hữu cơ đang được Nhà nước đặt biệt quan tâm trong giai đoạn sắp tới nhằm tăng giá trị thương phẩm và uy tín cho sản phẩm lúa gạo của Việt Nam.

Thực tế cho thấy một số tỉnh thành ở khu vực ĐBSCL, nhất là tỉnh Vĩnh Long, là một trong những địa phương đi đầu, đã mạnh dạn thay đổi từ hệ thống trồng lúa thông thường sang mô hình trồng theo hướng hữu cơ thí điểm ở một số khu vực. Hệ thống trồng lúa hữu cơ này bước đầu đã mang lại nhiều kết quả vượt trội hơn so với mô hình canh tác truyền thống như: lượng phân bón và thuốc bảo vệ thực vật sử dụng đã giảm, cây lúa tăng trưởng tốt hơn, ít sâu bệnh, và giá bán cao hơn lúa truyền thống (Cổng thông tin điện tử Vĩnh Long, 2018). Bên cạnh hiệu quả về kinh tế, về lâu dài, mô hình được kỳ vọng làm thay đổi nhận thức và tập quán của người nông dân chuyển từ sử dụng thuốc hóa học sang sử dụng phân sinh học, từ đó hạn chế được ô nhiễm nguồn nước và rác thải, nguồn lợi thủy sản được phục hồi, môi trường đất được cải thiện.

Tuy nhiên, đây là mô hình mới được áp dụng thử nghiệm, năng suất chưa cao như mong đợi. Do đó, việc tìm hiểu tình hình sản xuất và sự khác biệt về hiệu quả tài chính giữa phương thức canh tác lúa hữu cơ và mô hình thông thường cần được tìm hiểu nhằm xác định thêm những dữ liệu cần thiết cho các nhà làm chính sách để chuyển đổi mô hình sản xuất theo hướng hữu cơ phù hợp, cải thiện môi trường sống, giúp người dân bảo vệ sức khỏe khỏi các tác động của phân thuốc hóa học. Các nội dung tiếp theo của bài nghiên cứu này được trình bày như sau: (1) tìm hiểu tình hình trồng lúa theo phương pháp truyền thống và hữu cơ ở tỉnh Vĩnh 
Long; (2) tính toán và so sánh các chỉ tiêu tài chính của mô hình truyền thống và mô hình hữu cơ; (3) phân tích các yếu tố ảnh hưởng đến hiệu quả tài chính và các nhân tố tác động đến ý định chuyển đổi từ mô hình trồng lúa thường sang lúa hữu cơ của nông hộ. Dựa trên kết quả phân tích, những hàm ý chính sách sau đó được đề xuất để phát triển mô hình lúa theo hướng hữu cơ tại tỉnh Vĩnh Long và ĐBSCL.

\section{Phương pháp nghiên cứu}

Dựa trên các thông tin thu thập được từ tham khảo ý kiến của cán bộ địa phương thuộc Chi cục Trồng trọt và Bảo vệ thực vật tỉnh Vĩnh Long và quá trình khảo sát sơ bộ, 148 hộ được phỏng vấn trực tiếp theo phương pháp chọn mẫu ngẫu nhiên có điều kiện bao gồm 70 hộ hiện đang canh tác lúa theo hướng hữu cơ và 78 hộ canh tác theo phương thức truyền thống ở xã Loan Mỹ, Ngãi Tứ và Mỹ Lộc huyện Tam Bình. Nghiên cứu này sử dụng phương pháp thống kê mô tả và phương pháp so sánh để mô tả và phân tích những đặc điểm kinh tế xã hội của nông hộ và những yếu tố có liên quan đến sản xuất. Các chỉ tiêu tính toán về doanh thu, các khoản chi phí, chỉ tiêu lợi nhuận trên đơn vị diện tích được dùng để đo lường kết quả sản xuất của nông hộ và các chỉ số tài chính như: tỷ số doanh thu trên chi phí sản xuất (DT/CP), tỷ số lợi nhuận trên chi phí (LN/CP), lợi nhuận trên doanh thu (LN/DT), lợi nhuận trên lao động gia đình (LN/LĐGĐ) nhằm xác định hiệu quả tài chính của nông dân. Khi đánh giá hiệu quả tài chính, những nghiên cứu trước đây thường sử dụng những chỉ tiêu này để phân tích (A. T. T. Nguyen \& Vo, 2017; Ha \& Duong, 2014; La \& Mai, 2015; Ngo \& Truong, 2015). Tuy nhiên, theo lược khảo tài liệu nghiên cứu, hiện nay các nghiên cứu về hiệu quả tài chính của mô hình trồng lúa hữu cơ vẫn chưa được thực hiện nhiều, nhất là có sự so sánh với các mô hình truyền thống.

Nhằm xác định sự khác biệt về hiệu quả tài chính của mô hình thông thường và mô hình hữu cơ, tác giả sử dụng kiểm định $\mathrm{t}$ ( $\mathrm{t}$-test) để kiểm định trung bình hai mẫu độc lập đối với các giá trị có liên quan đến đặc điểm của nông hộ, chi phí sản xuất, doanh thu, thu nhập, và các chỉ tiêu tài chính.

Bên cạnh đó, hàm lợi nhuận biên ngẫu nhiên Cobb-Douglas được phân tích để xác định các yếu tố tác động đến lợi nhuận chuẩn hóa của nông hộ bằng phương pháp ước lượng hợp lý cực đại (Maximum Likelihood Estimation - MLE). Hàm lợi nhuận được xây dựng từ hàm sản xuất dựa trên cách tiếp cận đo lường hiệu quả bằng phương pháp đối ngẫu (duality approach). Trong đó, ứng với một trình độ công nghệ và những yếu tố đầu vào cố định nhất định, hàm lợi nhuận biểu diễn lợi nhuận biến đổi của nông trại như là một hàm số của giá đầu vào và giá đầu ra biến đổi, và khối lượng của các đầu vào cố định. Mô hình lý thuyết của hàm lợi nhuận được xây dựng như sau:

$$
y=f\left(x_{1}, x_{2}, \ldots ., x_{m} ; z_{1}, z_{2}, \ldots ., z_{n}\right)
$$

Trong đó $\mathrm{y}$ là khối lượng đầu ra, $\mathrm{x}_{\mathrm{i}}$ là những đầu vào biến đổi và $\mathrm{z}_{\mathrm{i}}$ là những đầu vào cố định. Hàm lợi nhuận có thể viết lại như sau:

$$
\pi=p_{y} f\left(x_{1}, x_{2}, \ldots ., x_{m} ; z_{1}, z_{2}, \ldots ., z_{n}\right)-\sum_{1}^{m} p_{i} x_{i}
$$

Trong đó $p_{y}$ là giá đầu ra và $p_{i}$ là giá đầu vào biến đổi thứ $i, i-1,2, \ldots, m$. Dựa vào điều kiện bậc nhất của tối đa hóa lợi nhuận của nhà sản xuất, hàm lợi nhuận chuẩn hóa được xây dựng. Lợi nhuận này có liên quan đến giá tương đối giữa đầu vào và đầu ra, chứ không phải giá tuyệt đối trong hàm lợi nhuận. Cụ thể hàm lợi nhuận biên ngẫu nhiên Cobb-Douglas được tính toán có dạng tổng quát như sau: 


$$
\ln \pi_{i}=\beta_{0}+\beta_{1} \ln X_{1}+\beta_{2} \ln X_{2}+\beta_{3} \ln X_{3}+\beta_{4} \ln X_{4}+\beta_{5} \ln X_{5}+\beta_{6} \ln X_{6}+\beta_{7} \ln X_{7}+\varepsilon_{i}
$$

Trong đó ${ }{ }_{i}$ là mức lợi nhuận chuẩn hóa (hay lợi nhuận đơn vị sản lượng UOP) của nông hộ thứ $i$, giá trị này được xác định bằng tổng doanh thu trừ đi các chỉ tiêu của chi phí biến đổi bao gồm phân bón, thuốc bảo vệ thực vật và chi phí giống, sau đó chia cho giá lúa, $\beta_{0}$ là hệ số tự do (hệ số góc của hàm Cobb-Douglas), ${ }^{\beta_{i}}$ là hệ số tương quan thứ i ứng với các biến độc lập như $\mathrm{X}_{\mathrm{i}}$ $(\mathrm{i}=0,1,2, \ldots, 7)$. Các giá trị $\beta_{i}$ đại diện cho mức ảnh hưởng của các yếu tố đầu vào đối với lợi nhuận. Chúng còn đo lường hệ số co giãn của lợi nhuận theo số lượng của các yếu tố đầu vào vì chúng cho biết khi các yếu tố đầu vào tăng lên $1 \%$ thì làm cho lợi nhuận thay đổi $\beta_{i}$ phần trăm $(\%)$, mức thay đổi này cùng chiều hay nghịch chiều tùy thuộc vào dấu của giá trị $\beta_{i}, \mathrm{X}_{\mathrm{i}}$ là giá chuẩn hóa của các yếu tố đầu vào và các yếu tố cố định khác, ${ }^{\varepsilon_{i}}$ là sai số hỗn hợp của mô hình. Dựa vào khung lý thuyết sản xuất và các nghiên cứu thực nghiệm có liên quan, các biến đưa vào mô hình nghiên cứu được diễn giải trong Bảng 1 . Ngoài các biến là giá chuẩn hóa của các nguồn lực đầu vào theo lý thuyết hàm sản xuất (Debertin, 2012), việc áp dụng kỹ thuật mới và có tập huấn cũng được xem xét. Lược khảo các tài liệu trước đây như của Ha và Duong (2014) và Duong và Nguyen (2014), việc áp dụng khoa học kỹ thuật và nông hộ khi được tập huấn cũng có tác động rõ rệt lên mức hiệu quả tài chính của mô hình sản xuất trong nông nghiệp.

\section{Bảng 1}

Các biến độc lập được sử dụng trong mô hình hàm lợi nhuận chuẩn hóa

\begin{tabular}{|c|c|c|c|}
\hline $\begin{array}{c}\text { Biến } \\
\text { độc lập }\end{array}$ & $\begin{array}{l}\text { Ký } \\
\text { hiệu }\end{array}$ & Mô tả biến & $\begin{array}{c}\text { Dấu } \\
\text { kỳ vọng }\end{array}$ \\
\hline $\operatorname{lnPnpk}$ & $\mathrm{X}_{1}$ & Giá phân NPK chuẩn hóa (giá $1 \mathrm{~kg}$ phân NPK/giá $1 \mathrm{~kg}$ lúa bán ra) & - \\
\hline $\ln$ Pure & $\mathrm{X}_{2}$ & Giá phân URE chuẩn hóa (giá $1 \mathrm{~kg}$ phân URE/giá $1 \mathrm{~kg}$ lúa bán ra) & - \\
\hline $\operatorname{lnPdap}$ & $\mathrm{X}_{3}$ & Giá phân DAP chuẩn hóa (giá $1 \mathrm{~kg}$ phân DAP/giá $1 \mathrm{~kg}$ lúa bán ra) & - \\
\hline lnPthuoc & $\mathrm{X}_{4}$ & Chi phí mua thuốc bảo vệ thực vật $(1,000$ đồng/1,000m²) & - \\
\hline lnPgiong & $\mathrm{X}_{5}$ & Giá chuẩn hóa của $1 \mathrm{~kg}$ giống (giá $1 \mathrm{~kg}$ giống/giá $1 \mathrm{~kg}$ lúa bán ra) & - \\
\hline lnldgd & $\mathrm{X}_{6}$ & $\begin{array}{l}\text { Số thành viên trong gia đình tham gia sản xuất lúa (số ngày } \\
\text { công } / 1,000 \mathrm{~m}^{2} \text { ) }\end{array}$ & + \\
\hline taphuan & $\mathrm{X}_{7}$ & $\begin{array}{l}\text { Biến giả }(1=\text { nông hộ có tham gia tập huấn; } 0=\text { không tham gia } \\
\text { tập huân) }\end{array}$ & + \\
\hline
\end{tabular}

Nguồn: Tổng hợp từ lược khảo tài liệu và khảo sát sơ bộ (2019)

\section{Trong đó:}

X1 (Pnpk): Là giá đầu vào của một ký phân Npk chuẩn hóa được tính bằng giá $1 \mathrm{~kg}$ phân Npk chia cho giá $1 \mathrm{~kg}$ lúa bán ra. Khi giá phân Npk tăng lên sẽ trực tiếp làm tăng tổng chi phí sản xuất và ảnh hưởng đến lợi nhuận của nông hộ bị giảm xuống. Do đó kỳ vọng hệ số của biến này là âm (-);

X2 (Pure): Là giá phân Ure được chuẩn hóa được xác định bằng giá $1 \mathrm{~kg}$ phân Ure chia cho giá $1 \mathrm{~kg}$ lúa bán ra. Giá các yếu tố đầu vào tăng lên sẽ làm ảnh hưởng trực tiếp đến lợi nhuận, do đó khi giá phân Ure tăng lên sẽ làm giảm lợi nhuận và biến này được kỳ vọng mang dấu âm (-); 
X3 (Pdap): Là giá của phân Dap được chuẩn hóa, được xác định bằng công thức giá $1 \mathrm{~kg}$ phân Dap chia giá $1 \mathrm{~kg}$ lúa bán ra. Khi giá Dap tăng lên sẽ làm giảm lợi nhuận của nông hộ do chi phí đầu vào tăng lên, và biến này kì vọng mang dấu âm (-);

X4 (Pthuoc): Là tổng chi phí thuốc nông dược được tính bằng tổng các loại thuốc cỏ, thuốc sâu, thuốc bệnh, thuốc dưỡng đơn vị tính là đồng/ $1,000 \mathrm{~m}^{2}$. Khi chi phí nông dược bỏ ra nhiều thì tổng chi phí sản xuất sẽ tăng điều này làm ảnh hưởng ngược chiều đến lợi nhuân, do đó biến chi phí thuốc nông dược được kỳ vọng mang dấu âm (-);

X5 (Pgiong): Giá giống chuẩn hóa được xác định bằng giá của $1 \mathrm{~kg}$ giống chia cho giá lúa bán ra, là số tiền mà nông hộ bỏ ra để mua giống gieo sạ. Trên thực tế, vẫn còn một số nông hộ còn sử dụng liều lượng cao hơn mức khuyến cáo và mua giống đại trà từ các vụ mùa trước để lại hoặc của các đại lý lúa giống gần nhà nên giá giống của nông hộ có thường thấp hoặc cao hơn giá của các trung tâm giống và biến này được kỳ vọng mang dấu âm (-);

X6 (Lnldgd): là số thành viên trong gia đình có tham gia sản xuất lúa, chỉ tiêu này được kỳ vọng sẽ làm tăng hiệu quả của phương thức canh tác do được đầu tư quan tâm nhiều hơn khi công lao động gia đình đầu tư nhiều hơn;

X7 (Taphuan): biến giả, thể hiện chủ hộ hoặc người sản xuất chính có được tập huấn không. Biến này được kỳ vọng mang dấu dương và có tác động đến lợi nhuận của mô hình sản xuất.

Bên cạnh đó, hàm nhị phân Logistic được phân tích nhằm xây dựng các luận cứ khoa học đề xuất giải pháp tạo động cơ thúc đẩy người dân tham gia vào mô hình sản xuất theo hướng hữu cơ trong tương lai, các yếu tố tác động đến quyết định tham gia mô hình trồng lúa hữu cơ cũng được phân tích trong mô hình này có dạng tổng quát như sau:

$$
\operatorname{Ln}\left[\frac{P(Y=1)}{P(Y=0)}\right]=\beta_{0}+\beta_{1} X_{1}+\beta_{2} X_{2}+\ldots+\beta_{i} X_{i}
$$

Trong đó: $\mathrm{P}(\mathrm{Y}=1)=\mathrm{P}_{0}$ : Xác suất xảy ra sự kiện là xác suất để hộ gia đình đồng ý chuyển đổi sang trồng lúa hữu cơ, $\mathrm{P}(\mathrm{Y}=0)=1-\mathrm{P}_{0}$ : Xác suất không xảy ra sự kiện là xác suất để hộ gia đình không tham gia mô hình trồng lúa hữu cơ, $\mathrm{X}_{\mathrm{i}}$ : Các biến độc lập $(\mathrm{i}=0,1,2, \ldots, \mathrm{n})$, Ln: $\log$ của cơ số e $(\mathrm{e}=2.714)$, với hệ số Odds như sau:

$$
O_{0}=\frac{P_{0}}{1-P_{0}} \quad \text { Odds }=\frac{\mathrm{P}_{0}}{1-\mathrm{P}_{0}}=\frac{\mathrm{P}(\text { Xác suất chuyển đổi sang mô hình hữu cơ })}{\mathrm{P}(\text { Xác suất không chuyển đồi sang mô hình hữu cơ })}
$$

Có thể viết lại hàm Logistic dưới dạng:

$$
\operatorname{Ln}(\text { Odds })=\beta_{0}+\beta_{1} X_{1}+\beta_{2} X_{2}+\beta_{3} X_{3}+\beta_{4} X_{4}+\beta_{5} X_{5}
$$

Các hệ số hồi quy này sẽ được tính toán bằng cách sử dụng phương pháp ước lượng hợp lý cực đại (Maximum Likehood Estimation). Chủ hộ là yếu tố quan trọng nhất quyết định hướng sản xuất theo mô hình nào trong nông hộ, ngoài ra lực lượng lao động cũng rất cần thiết và quan trọng trong các mô hình sản xuất nông nghiệp (Debertin, 2012). Do đó, các biến được đưa vào mô hình bao gồm tuổi, trình độ học vấn của chủ hộ (Bảng 2). Do mô hình hữu cơ còn khá mới, còn một số hạn chế ban đầu, tuy nhiên về lâu dài sẽ mang lại lợi ích to lớn, đảm bảo chuyển đổi nông nghiệp theo hướng chất lượng cao, bảo vệ sức khỏe nông dân và giảm ô nhiễm môi trường. Do đó, dựa trên lược khảo tài liệu nghiên cứu và số liệu phân tích, chỉ có 05 biến độc lập được đưa vào mô hình nhị phân và các biến này đều có liên quan đến nguồn lực của nông hộ. 


\section{Bảng 2}

Các biến trong mô hình nhị phân Logistic

\begin{tabular}{|l|c|l|c|}
\hline \multicolumn{1}{|c|}{ Tên biến } & $\begin{array}{c}\text { Ký } \\
\text { hiệu }\end{array}$ & \multicolumn{1}{c|}{ Diễn giải } & $\begin{array}{c}\text { Kỳ } \\
\text { vọng }\end{array}$ \\
\hline Dientich & $\mathrm{X}_{1}$ & Diện tích canh tác lúa $\left(1,000 \mathrm{~m}^{2}\right)$ & + \\
\hline Tuoi & $\mathrm{X}_{2}$ & Tuổi của chủ hộ (năm) & + \\
\hline Hocvan & $\mathrm{X}_{3}$ & Trình độ học vấn của chủ hộ & + \\
\hline Thanhvien & $\mathrm{X}_{4}$ & Số thành viên trong hộ (người) & + \\
\hline Thunhapkhac & $\mathrm{X}_{5}$ & $\begin{array}{l}\text { Thu nhập khác (1 = nông hộ có nguồn thu nhập khác, } 0 \\
\text { = không có thu nhập khác) }\end{array}$ & - \\
\hline
\end{tabular}

Nguồn: Tổng hợp từ lược khảo tài liệu và khảo sát sơ bộ (2019)

\section{Kết quả nghiên cứu}

\subsection{Thông tin chung về đặc điểm của nông hộ}

Kết quả khảo sát cho thấy lao động tham gia sản xuất lúa ở cả hai mô hình chủ yếu là tuổi trung niên (khoảng trên dưới 50 tuổi). Trình độ học vấn giữa hai nhóm nông hộ cũng tương đối đồng nhất (trung bình cấp 02) và giá trị trung bình của diện tích canh tác khoảng 7.4 ha và 6.4 ha lần lượt ở nhóm truyền thống và hữu cơ. Số lao động trực tiếp tham gia sản xuất từ 01 đến 03 lao động trong một nông hộ. Sự khác biệt của những giá trị này không có ý nghĩa về mặt thống kê, nói một cách khác, có sự đồng nhất về đặc điểm kinh tế xã hội giữa hai nhóm nông hộ, từ đó đảm bảo không có sự sai lệch nhiều (bias) khi tìm hiểu sự khác biệt về hiệu quả tài chính từ hai nhóm này.

Kết quả khảo sát cho thấy, mô hình lúa truyền thống có 24/78 hộ được tập huấn kỹ thuật chiếm $31 \%$ và có $54 / 78$ nông dân không tham gia tập huấn kỹ thuật chiếm $69 \%$, với nhiều nguyên nhân được xác định, như cảm thấy không cần thiết, dựa vào kinh nghiệm và các buổi tập huấn phần lớn là để giới thiệu quảng bá phân thuốc mới của các công ty thuốc bảo vệ thực vật. Trong đó, $100 \%$ các hộ tham gia mô hình trồng lúa hữu cơ có tập huấn kỹ thuật (sự khác biệt với ý nghĩa thống kê $1 \%$ ). Đây là lợi thế, tuy nhiên cũng là khó khăn ban đầu của các hộ canh tác theo hướng hữu cơ do nếu làm sai quy trình, không tuân thủ các quy tắc, sử dụng các loại phân thuốc BVTV thì sản phẩm sẽ không được công ty thu mua hoặc mua với giá rẻ. Thứ hai, đây là mô hình còn khá mới đối với người nông dân do chưa quen về liều lượng sử dụng phân thuốc cũng như chưa biết nhiều về các loại bệnh nên cần được tham gia tập huấn. Đó cũng là lý do $100 \%$ hộ canh tác theo hướng hữu cơ hiện nay có tham gia hợp tác xã để được bao tiêu và được hướng dẫn về mặt kỹ thuật trong khi chỉ 1 hộ trong mô hình truyền (HTX) thống tham gia HTX. Một hạn chế khác của mô hình truyền thống là các nông hộ còn bị động trong khâu tìm hiểu về thông tin giá cả thị trường, chủ yếu bằng tivi, radio và cò lúa. Ngược lại, các hộ khi gia nhập HTX sẽ được cung cấp thông tin từ chính các HTX, công ty thu mua sẽ thông báo trước giá thu mua cho nông hộ bằng cách tổ chức họp mặt. Như vậy, các tỉnh muốn triển khai các mô hình sản xuất đạt kết quả, cần khuyến khích nông dân tham gia vào các tổ sản xuất, kết quả này phù hợp với kết luận trong nghiên cứu của Duong và Nguyen (2014). 


\subsection{So sánh chi phí của hai mô hình}

\section{Bảng 3}

So sánh lượng giống giữa hai mô hình

\begin{tabular}{|l|c|c|c|c|c|c|}
\hline \multirow{2}{*}{ Chi phí giống } & \multicolumn{2}{|c|}{ Truyền thống } & \multicolumn{2}{c|}{ Hữu co } & \multicolumn{2}{c|}{ Chênh lệch } \\
\cline { 2 - 7 } & Đông Xuân & Hè Thu & Đông Xuân & Hè Thu & Đông Xuân & Hè Thu \\
\hline $\begin{array}{l}\text { Lượng giống } \\
\text { (kg/1000m }\end{array}$ & 18.11 & 18.59 & 13.0 & 12.52 & $5.11^{* * *}$ & $6.07^{* * *}$ \\
\hline $\begin{array}{l}\text { Đơn giá } \\
\text { (đồng/kg) }\end{array}$ & 12,282 & 12,295 & 13,000 & 14,000 & $-718^{* * *}$ & $-1,705^{* * *}$ \\
\hline
\end{tabular}

Ghi chú: *** tương ứng với mức ý nghĩa $1 \%$

Nguồn: Số liệu tổng hợp từ khảo sát (2019)

Cả hai vụ Đông Xuân và Hè Thu lượng giống gieo sạ từ hình thức truyền thống lớn hơn ở mô hình hữu cơ và mức chênh lệch khoảng $05 \mathrm{~kg} / 1,000 \mathrm{~m}^{2}$ với mức ý nghĩa $1 \%$. Nguyên nhân dẫn đến sự chênh lệch là do các hộ canh tác lúa thông thường còn dựa vào kinh nghiệm của bản thân với tâm lý sạ dày trúng hơn sạ thưa dẫn đến sự lãng phí nguồn lực. Đối với mô hình hữu cơ các nông hộ căn cứ vào các kỹ thuật canh tác đã được tập huấn, ngoài ra một số hộ áp dụng kỹ thuật sạ hàng nên giảm được lượng giống từ đó giảm được dịch bệnh và dẫn tới giảm chi phí sản xuất. Hiện tại, giá giống ở cách thức canh tác theo hướng hữu cơ cao hơn cách thức cũ do giống hữu cơ do HTX phân phối và có chất lượng cao hơn, trong khi các hộ mô hình truyền thống sử dụng giống vụ trước để lại hoặc mua của các hộ khác nên giá của mô hình hữu cơ cao hơn khoảng 1 - 1.5 ngàn đồng/ $1,000 \mathrm{~m}^{2}$, mặc dù có ý nghĩa thống kê $1 \%$ nhưng mức độ chênh lệch không nhiều, có thể chấp nhận được.

\section{Bảng 4}

So sánh công lao động gia đình giữa 2 mô hình (ngày công/1,000m²)

\begin{tabular}{lccc}
\multicolumn{1}{c}{ Vụ } & Truyền thống & Hữu co & Chênh lệch \\
\hline Đông Xuân & 5.83 & 6.14 & $-0.31^{\text {ns }}$ \\
Hè Thu & 6.56 & 6.89 & $-0.33^{\text {ns }}$
\end{tabular}

Nguồn: Số liệu khảo sát thực tế (2019)

Do mô hình hữu cơ tương đối mới nên đòi hỏi công lao động gia đình nhiều hơn ở tất cả các khâu chăm sóc, ngoài ra, do dùng ít phân thuốc và $100 \%$ phân sinh học nên cần dành nhiều thời gian trong các khâu chăm sóc mới đạt được năng suất tốt. Tuy nhiên sự khác biệt giữa hai mô hình không có ý nghĩa thống kê (Bảng 4).

\section{Bảng 5}

Cơ cấu chi phí so sánh giữa hai mô hình và hai vụ (đồng/1,000m²)

\begin{tabular}{|l|c|c|c|c|c|}
\hline \multicolumn{7}{|c|}{ Khoản mục } & Truyền thống & Tỷ trọng (\%) & Hũu cơ & Tỷ trọng (\%) & Chênh lệch \\
\hline \multicolumn{7}{|c|}{ Vụ Đông Xuân } \\
\hline Chi phí làm đất & 153,077 & 11.79 & 170,857 & 11.56 & $-17,780^{* * *}$ \\
\hline Chi phí gieo sạ & 222,154 & 17.11 & 169,000 & 11.44 & $53,154^{* * *}$ \\
\hline Chi phí làm cỏ tưới tiêu & 32,647 & 2.51 & 27,224 & 1.84 & $5,404^{\mathrm{ns}}$ \\
\hline
\end{tabular}




\begin{tabular}{|l|c|c|c|c|c|}
\hline \multicolumn{1}{|c|}{ Khoản mục } & Truyền thống & Tỷ trọng (\%) & Hữu co & Tỷ trọng (\%) & Chênh lệch \\
\hline Chi phí phân bón & 472,941 & 36.42 & 806,095 & 54.55 & $-333,154^{* * *}$ \\
\hline Chi phí thuốc nông dược & 170,596 & 13.14 & 55,924 & 3.79 & $114,672^{* * *}$ \\
\hline Chi phí thu hoạch & 247,173 & 19.03 & 248,586 & 16.82 & $-1,413^{\text {ns }}$ \\
\hline Tổng cộng & $\mathbf{1 , 2 9 8 . 5 8 8}$ & $\mathbf{1 0 0}$ & $\mathbf{1 , 4 7 7 . 7 0 6}$ & $\mathbf{1 0 0}$ & $\mathbf{- 1 7 9 , 1 1 8 ^ { * * * }}$ \\
\hline \multicolumn{7}{|c|}{ Vụ Hè Thu } \\
\hline Chi phí làm đất & 153,077 & 11.62 & 170,867 & 10.61 & $-17,790^{* * *}$ \\
\hline Chi phí gieo sạ & 228,308 & 17.34 & 175,280 & 10.88 & $53,028^{* * *}$ \\
\hline Chi phí làm cỏ tưới tiêu & 32,741 & 2.49 & 29,098 & 1.81 & $3,643^{\text {ns }}$ \\
\hline Chi phí phân bón & 487,947 & 37.05 & 833,116 & 51.73 & $-345,169^{* * *}$ \\
\hline Chi phí thuốc nông dược & 168,628 & 12.81 & 153,600 & 9.54 & $15,028^{\text {ns }}$ \\
\hline Chi phí thu hoạch & 246,187 & 18.69 & 248,586 & 15.43 & $-2,399^{\text {ns }}$ \\
\hline Tổng cộng & $\mathbf{1 , 3 1 6 . 8 8 8}$ & $\mathbf{1 0 0}$ & $\mathbf{1 , 6 1 0 . 5 3 8}$ & $\mathbf{1 0 0}$ & $\mathbf{- 2 9 3 , 6 5 0}^{* * * *}$ \\
\hline
\end{tabular}

Ghi chú: *** tương ứng với mức ý nghĩa $1 \%,{ }^{n s}$ không có ý nghĩa thống kê

Nguồn: Số liệu tổng hợp từ khảo sát (2019)

Trong cơ cấu chi phí của cả hai vụ Đông Xuân, vụ Hè Thu và cả hai cách thức canh tác, phân bón chiếm tỷ trọng cao nhất trong tổng chi phí. Ở vụ Đông Xuân, mô hình hữu cơ và mô hình truyền thống chiếm lần lượt $55 \%$ và $35 \%$, mức chênh lệch khoảng 300 ngàn đồng $/ 1,000 \mathrm{~m}^{2}$ với mức ý nghĩa $1 \%$. Mức chênh lệch này cũng không thay đổi nhiều ở vụ Hè Thu. Cơ cấu các khoản chi phí khác cũng tương tự nhau giữa hai mô hình trong tổng chi phí. Một số kết quả nghiên cứu đáng quan tâm ở đây, (1) tỷ trọng của chi phí thuốc nông dược giảm đáng kể ở mô hình hữu cơ, nhất là ở vụ Đông Xuân có sự chênh lệch ở mức ý nghĩa 1\%; (2) mức chênh lệch ở chi phí gieo sạ cũng rất đáng kể, điều này là do lượng giống ở mô hình hữu cơ sử dụng vừa phải và đúng kỹ thuật, mức chênh lệch ở hai vụ có ý nghĩa $1 \%$ và khoảng 50 ngàn $/ 1,000 \mathrm{~m}^{2}$; (3) có hai khoản chi phí mô hình hữu cơ cao hơn là chi phí làm đất và chi phí phân bón, sự chênh lệch đều có ý nghĩa $1 \%$, kết quả này là do khâu làm đất phải kỹ lưỡng hơn ở mô hình hữu cơ để đảm bảo độ sạch, phân hữu cơ giá hiện tại tương đối cao. Các khoản mục chi phí khác mô hình truyền thống cao hơn, tuy nhiên, vì việc sử dụng phân hữu cơ quá cao, do đó, tổng chi phí mô hình truyền thống hiện tại vẫn nhỏ hơn mô hình theo hướng hữu cơ. Tuy nhiên, khi nông dân đã quen với cách thức sản xuất lúa hữu cơ và quản lý liều lượng phân sử dụng tốt hơn, giá tốt hơn, tổng chi phí mô hình này được kỳ vọng sẽ giảm xuống đáng kể.

\subsection{So sánh năng suất, doanh thu, lọi nhuận và tình hình tiêu thụ}

\section{Bảng 6}

So sánh năng suất giữa 02 mô hình $\left(\mathrm{kg} / 1,000 \mathrm{~m}^{2}\right)$

\begin{tabular}{|c|l|c|c|c|c|c|}
\hline \multicolumn{1}{|c|}{ Vụ } & \multicolumn{1}{|c|}{ Mô hình } & Trung bình & Độ lệch chuẩn & Thấp nhất & Cao nhất & Chênh lệch \\
\hline \multirow{2}{*}{ Đông Xuân } & Truyền thống & 737.1 & 118.9 & 550 & 1,000 & \multirow{2}{*}{$199.8^{* * *}$} \\
\cline { 2 - 7 } & Hữu cơ & 537.3 & 120.8 & 290 & 900 & \\
\hline \multirow{2}{*}{ Hè Thu } & Truyền thống & 711.7 & 103.7 & 500 & 1,000 & \multirow{2}{*}{$168.2^{* * *}$} \\
\cline { 2 - 7 } & Hữu cơ & 543.5 & 125.5 & 320 & 940 & \\
\hline
\end{tabular}

Ghi chú: *** tương ứng với mức ý nghĩa $1 \%$

Nguồn: Số liệu tổng hợp từ khảo sát (2019) 
Theo nhận định của chuyên gia nông nghiệp tại địa bàn nghiên cứu, canh tác theo hướng hữu cơ giai đoạn đầu năng suất thấp hơn $25 \%$ so với canh tác thông thường, kết quả của nghiên cứu này cũng tương tự. Cụ thể, mức năng suất trung bình ở vụ Đông Xuân của mô hình truyền thống là $737.1 \mathrm{~kg} / 1,000 \mathrm{~m}^{2}$ (thấp nhất là $550 \mathrm{~kg} / 1,000 \mathrm{~m}^{2}$, cao nhất là $1,000 \mathrm{~kg} / 1,000 \mathrm{~m}^{2}$ ), trong khi chỉ tiêu này của mô hình hữu cơ chỉ đạt $537.3 \mathrm{~kg} / 1,000 \mathrm{~m}^{2}$ thấp hơn $199.8 \mathrm{~kg} / 1,000 \mathrm{~m}^{2}$ so với truyền thống, sự chênh lệch này có ý nghĩa thống kê ở mức $1 \%$. Ở vụ Hè Thu năng suất trung bình của mô hình truyền thống là $711.7 \mathrm{~kg} / 1,000 \mathrm{~m}^{2}$ cao hơn mô hình hữu cơ $168.2 \mathrm{~kg} / 1,000 \mathrm{~m}^{2}$ với mức ý nghĩa thống kê $1 \%$. Sự khác biệt này là do nông dân mới thực hiện chuyển đổi từ canh tác truyền thống sang hữu cơ, còn nhiều vấn đề chưa quen và lượng phân thuốc hữu cơ sử dụng tác động chưa thực sự mạnh như phân thuốc hóa học. Tuy nhiên, mô hình canh tác hữu cơ mang đến nhiều tác động tích cực và bền vững khi canh tác trong thời gian dài.

\section{Bảng 7}

Các khoản mục đo lường lợi nhuận ở hai mô hình (đồng/1,000m²)

\begin{tabular}{|c|c|c|c|c|c|c|}
\hline Khoản mục & Mô Hình & Trung bình & Độ lệch chuẩn & Thấp nhất & Cao nhất & Chênh lệch \\
\hline \multicolumn{7}{|c|}{ Vụ Đông Xuân } \\
\hline \multirow{2}{*}{ Doanh thu } & Truyền thống & $3,625,321$ & 582,798 & $2,716,000$ & $4,850,000$ & \multirow{2}{*}{$-247.662^{\mathrm{ns}}$} \\
\hline & Hữu cơ & $3,872,983$ & $8,439,659$ & $2,088,000$ & $6,480,000$ & \\
\hline \multirow{2}{*}{ Thu nhập } & Truyền thống & $2,326,733$ & 592,219 & $1,193,167$ & $3,631,091$ & \multirow{2}{*}{$-68.544^{\mathrm{ns}}$} \\
\hline & Hữu cơ & $2,395,276$ & 839,659 & 600,900 & $4,857,400$ & \\
\hline \multirow{2}{*}{ Lọi nhuận } & Truyền thống & $1,452,439$ & 444,858 & 743,167 & $2,581,091$ & \multirow{2}{*}{$-21.409^{\mathrm{ns}}$} \\
\hline & Hữu cơ & $1,473,848$ & 808,631 & 900 & $3,657,400$ & \\
\hline \multicolumn{7}{|c|}{ Vụ Hè Thu } \\
\hline \multirow{2}{*}{ Doanh thu } & Truyền thống & $3,747,987$ & 543,927 & $2,650,000$ & $5,300,000$ & \multirow{2}{*}{$-163.575^{\mathrm{ns}}$} \\
\hline & Hữu cơ & $3,922,562$ & 902,998 & $2,304,000$ & $6,768,000$ & \\
\hline \multirow{2}{*}{ Thu nhập } & Truyền thống & $2,431,100$ & 506,594 & $1,557,686$ & $3,830,250$ & \multirow[b]{2}{*}{$130.076^{\mathrm{ns}}$} \\
\hline & Hữu cơ & $2,301,024$ & 893,096 & 690,000 & $5,034,500$ & \\
\hline \multirow{2}{*}{ Lọii nhuận } & Truyền thống & $1,447,149$ & 409,792 & 677,289 & $2,517,750$ & \multirow{2}{*}{$178.982^{\mathrm{ns}}$} \\
\hline & Hữu cơ & $1,268,167$ & 847,380 & 19,500 & $3,834,500$ & \\
\hline
\end{tabular}

Ghi chú: ${ }^{n s}$ tương ứng không có ý nghĩa thống kê

Nguồn: Số liệu tổng hợp từ khảo sát (2019)

Phát hiện khá thú vị của nghiên cứu này là mặc dù chi phí phát sinh ở hai mô hình có sự chênh lệch với mức ý nghĩa $1 \%$ và cao hơn ở mô hình hữu cơ. Tuy nhiên, ở vụ Đông Xuân, chỉ tiêu doanh thu, thu nhập và lợi nhuận của mô hình hữu cơ cao hơn so với mô hình truyền thống, vụ Hè Thu thì doanh thu của mô hình mới cao hơn mô hình cũ, còn lại thu nhập và lợi nhuận thấp hơn mô hình truyền thống. Tuy nhiên, tất cả sự khác biệt này đều không có ý nghĩa về mặt thống kê. Cụ thể là doanh thu của mô hình truyền thống và hữu cơ ở vụ Đông Xuân lần lượt là $3,625,321$ đồng/1,000 $\mathrm{m}^{2}$ và 3,872,983 đồng/1,000 $\mathrm{m}^{2}$, vụ Hè Thu mức chênh lệch khoảng 160 ngàn/1,000m² và thấp hơn mức chênh lệch ở vụ Đông Xuân. Nguyên nhân của sự chênh lệch này không phải do năng suất (mô hình hữu cơ thấp hơn $199 \mathrm{~kg} / 1,000 \mathrm{~m}^{2}$ ) mà là do giá lúa hữu cơ $(7,200$ đồng $/ \mathrm{kg})$ cao hơn truyền thống $(4,921$ đồng $/ \mathrm{kg})$.

Thu nhập được hiểu là phần chênh lệch giữa tổng doanh thu và tổng chi phí (không tính công lao động gia đình). Ở vụ Đông Xuân, thu nhập của nông hộ hữu cơ cao hơn truyền thống 
lần lượt là 2,395,276 đồng/ $1,000 \mathrm{~m}^{2}$ và $2,326,733$ đồng $/ 1,000 \mathrm{~m}^{2}$, vụ Hè Thu cũng có mức thu nhập tương tự. Tuy nhiên, vụ Hè Thu mô hình hữu cơ thấp hơn truyền thống khoảng 130 ngàn đồng $/ 1,000 \mathrm{~m}^{2}$, nhưng sự khác biệt không có ý nghĩa thống kê. Lợi nhuận được tính là phần lãi mà nông hộ nhận được sau khi trừ đi tất cả các khoảng chi phí sản xuất (có công lao động gia đình). Ở cả hai vụ mức lợi nhuận nông hộ đạt được trung bình khoảng 1,450,000 đồng/1,000 m², chỉ vụ hè Thu nhóm hữu cơ khoảng 1,300,000 đồng/1,000m² (sự khác biệt không có ý nghĩa thống kê).

\subsection{Các chỉ số tài chính của hai mô hình qua tùng vụ}

\section{Bảng 8}

Các chỉ số tài chính của 2 mô hình ở hai vụ

\begin{tabular}{|l|c|c|c|c|c|c|}
\hline & \multicolumn{3}{|c|}{ Đông Xuân } & \multicolumn{3}{c|}{ Hè Thu } \\
\hline \multicolumn{1}{|c|}{ Chỉ tiêu } & Truyền thống & Hưu co & Chênh lệch & Truyền thống & Hũ̃u co & Chênh lệch \\
\hline $\begin{array}{l}\text { Lao động gia đình } \\
\text { (ngày/1,000m }{ }^{2} \text { ) }\end{array}$ & 5.83 & 6.14 & $-0.31^{\text {ns }}$ & 6.56 & 6.89 & $-0.33^{\text {ns }}$ \\
\hline Doanh thu/chi phí (lần) & 2.82 & 2.62 & $0.20^{\text {ns }}$ & 2.85 & 2.43 & $0.42^{* * *}$ \\
\hline Thu nhập/chi phí (lần) & 1.82 & 1.62 & $0.20^{\text {ns }}$ & 1.85 & 1.43 & $0.42^{* * *}$ \\
\hline Lợi nhuận/chi phí (lần) & 1.14 & 0.99 & $0.15^{\text {ns }}$ & 1.11 & 0.79 & $0.32^{* * *}$ \\
\hline $\begin{array}{l}\text { Lợi nhuận/lao động gia } \\
\text { đình (đồng/ngày công) }\end{array}$ & 254,783 & 259,353 & $-4,570^{\text {ns }}$ & 228,388 & 191,698 & $36,690^{\text {ns }}$ \\
\hline
\end{tabular}

Ghi chú: *** tương ứng với mức ý nghĩa $1 \%$, ${ }^{\text {ns }}$ không có ý nghĩa thống kê

Nguồn: Số liệu tổng hợp từ khảo sát (2019)

Điểm phát hiện thú vị thứ hai trong nghiên cứu này là sự chênh lệch có ý nghĩa về mặt thống kê chỉ ở vụ Hè Thu, vụ Đông Xuân không có ý nghĩa về mặt thống kê. Mặt khác, mặc dù sự khác biệt về các chỉ tiêu lợi nhuận, chi phí và doanh thu ở hai mô hình không có ý nghĩa về mặt thống kê, các tỷ số tài chính lại có do giá trị tuyệt đối của các chỉ tiêu này rất nhỏ so với các chỉ về doanh thu, chi phí và lợi nhuận. Cụ thể, chỉ tiêu doanh thu/chi phí cho biết 01 đồng chi phí nông hộ đầu tư vào sản xuất sẽ thu lại được bao nhiêu đồng doanh thu. Khi chỉ số này thấp hơn 01 thì người sản xuất không có lời, nếu chỉ số này bằng 01 thì người sản xuất hòa vốn và nếu chỉ số này lớn hơn 01 thì người sản xuất có lời. Ví dụ, vụ Đông Xuân mô hình truyền thống chỉ số doanh thu/chi phí là 2.82 nghĩa là 01 đồng chi phí đầu tư sản xuất của nông hộ thì nhận được 2.82 đồng doanh thu, còn ở mô hình hữu cơ chỉ số này là 2.62 nghĩa là 01 đồng chi phí đầu tư sản xuất thì nông hộ ở mô hình hữu cơ sẽ thu lại được 2.62 đồng doanh thu. Chỉ số thu nhập/chi phí cho biết 01 đồng chi phí bỏ ra để đầu tư vào sản xuất sẽ thu được bao nhiêu đồng thu nhập. Trong vụ lúa Đông Xuân một đồng chi phí bỏ ra sản xuất lúa truyền thống sẽ nhận lại 1.82 đồng thu nhập con số này cao hơn ở mô hình hữu cơ, với 01 đồng chi phí đầu tư thì hộ trồng lúa hữu cơ sẽ thu được 1.62 đồng thu nhập. Chỉ số Lợi nhuận/chi phí cho biết 01 đồng chi phí bỏ ra của nông hộ sẽ mang lại bao nhiêu đồng lợi nhuận. Chỉ số Lợi nhuận/lao động gia đình cho biết 01 ngày công lao động gia đình sản xuất thì sẽ mang lại bao nhiêu đồng lợi nhuận. Đáng chú ý, mặc dù số ngày công lao động gia đình trung bình $/ 1,000 \mathrm{~m}^{2}$ từ hộ trồng lúa hữu cơ lớn hơn hộ trồng lúa truyền thống nhưng lợi nhuận/công lao động gia đình ở mô hình hữu cơ lại cao hơn cho thây rằng ở mô hình hữu cơ nông hộ sử dụng lao động gia đình tốt hơn ở phương thức canh tác cũ. Ở vụ Hè Thu, giá trị doanh thu/chi phí có sự khác biệt do mô hình hữu cơ các chi phí đầu vào sản xuất còn quá cao nên tỷ số này còn thấp hơn ở mô hình truyền thống. Một chỉ số đáng chú ý ở vụ Hè Thu là Lợi nhuận/công lao động gia đình có sự chênh lệch do ngày công ở hộ hữu cơ cao hơn do tốn nhiều công chăm sóc hơn. 


\subsection{Nhũng yếu tố ảnh hưởng đến lợi nhuận của mô hình}

Trong mô hình xác định các yếu tố ảnh hưởng đến lợi nhuận từ sản xuất lúa, nhóm nông hộ hữu cơ không được phân tích vì các đầu vào sử dụng tương đối giống nhau do được tập huấn và làm theo tập huấn từ HTX, do đó, nghiên cứu này sẽ tập trung tìm hiểu các yếu tố ảnh hưởng đến lợi nhuận của mô hình truyền thống, làm luận cứ khoa học đề xuất các hàm ý chính sách khuyến khích chuyển đổi sang mô hình hữu cơ (Bảng 9).

\section{Bảng 9}

Các yếu tố ảnh hưởng đến lợi nhuận chuẩn hóa

\begin{tabular}{lcccc}
\hline \multirow{2}{*}{ Biến số } & \multicolumn{2}{c}{ Đông Xuân } & \multicolumn{2}{c}{ Hè Thu } \\
\cline { 2 - 5 } & Hệ số & Sai số chuẩn & Hệ số & Sai số chuẩn \\
\hline lnnpk & $-0.739^{* *}$ & 0.359 & $-0.885^{* *}$ & 0.356 \\
lnure & $0.449^{\mathrm{ns}}$ & 0.688 & $-0.071^{\mathrm{ns}}$ & 0.567 \\
lndap & $0.036^{\mathrm{ns}}$ & 0.044 & $-0.006^{\mathrm{ns}}$ & 0.049 \\
lnthuoc & $-0.180^{* *}$ & 0.073 & $0.016^{\mathrm{ns}}$ & 0.068 \\
lngiong & $-1.203^{* * *}$ & 0.369 & $-1.458^{* * *}$ & 0.311 \\
lnldgd & $0.470^{* * *}$ & 0.087 & $0.202^{* *}$ & -0.094 \\
taphuan & $0.096^{* *}$ & 0.408 & $0.090^{* * *}$ & 0.040 \\
Hằng số & $9.241^{* * *}$ & 1.169 & $7.711^{* * *}$ & 0.937 \\
Số quan sát & 78 & & 78 & \\
Log likehood & 32.921 & & 34.609 & \\
Prob > chi2 & 0.000 & & 0.000 & \\
Sigma & 0.1040 & & 0.0996 & \\
\hline
\end{tabular}

Ghi chú: ***, ** tương ứng với mức ý nghĩa $1 \%$ và $5 \%,{ }^{\mathrm{ns}}$ không có ý nghĩa thống kê

Nguồn: Tính toán từ số liệu khảo sát (2019)

Kết quả phân tích cho thấy có mối quan hệ tuyến tính giữa lợi nhuận chuẩn hóa và ít nhất một biến độc lập trong mô hình phân tích và các biến này có khả năng giải thích khá tốt cho lợi nhuận của nông hộ (Prob $>$ chi $^{2}=0.0000<1 \%$ ). Có ít nhất hai biến tác động tích cực đến lợi nhuận gồm tập huấn và công lao động gia đình, hai biến ảnh hưởng ngược chiều tới lợi nhuận chuẩn hóa bao gồm giá chuẩn hóa của phân NPK, giá giống chuẩn hóa và có ý nghĩa thống kê ở mức 5\% hoặc $1 \%$. Bên cạnh đó, nếu giá giống, giá phân giảm $1 \%$ thì lợi nhuận sẽ tăng lần lượt $0.7 \%$ ở vụ Đông Xuân và $0.9 \%$ ở vụ Hè Thu. Hệ số tập huấn đều có ý nghĩa thống kê ở mức $5 \%$ và $1 \%$ ở vụ Đông Xuân và Hè Thu và mang dấu dương cho thấy nếu được tham gia tập huấn sẽ giúp cho lợi nhuận của nông hộ tăng lên. Như vậy, nhìn chung các nông hộ ở mô hình truyền thống còn sử dụng đầu vào chưa hợp lý và chưa đúng kỹ thuật làm giảm lợi nhuận của mô hình canh tác. Ngoài ra, mô hình hữu cơ đòi hỏi nhiều lao động gia đình và hộ phải tham gia hợp tác xã và tập huấn, từ đo sẽ tăng lợi nhuận của mô hình canh tác. Tuy nhiên, việc này đòi hỏi cần có thêm phân tích kỹ thuật cho cả hai mô hình để có kết luận chính xác nhất, làm cơ sở đề xuất thêm nhiều giải pháp có liên quan, điều này được kỳ vọng sẽ thực hiện trong các nghiên cứu tiếp theo của nhóm. Các biến giá chuẩn hóa của phân Ure và Dap mang dấu dương nhưng không có ý nghĩa, nguyên nhân do các loại phân này không có sự khác biệt nhiều giữa các nông hộ so với loại phân chính là NPK. 


\subsection{Các yếu tố ảnh hưởng đến ý định tham gia mô hình sản xuất hũu cơ của nhóm nông hộ truyền thống}

Kết quả ước lượng bằng mô hình hồi quy Logistic nhằm xác định mức độ ảnh hưởng của các biến đến quyết định tham gia mô hình theo hướng hữu cơ được trình bày trong Bảng 10.

\section{Bảng 10}

Kết quả mô hình nhị phân Logistic

\begin{tabular}{|l|c|c|c|}
\hline \multicolumn{1}{|c|}{ Biến } & Hệ số & Ảnh hưởng biên & Sai số chuẩn \\
\hline Diện tích & 0.396 & $0.075^{* *}$ & 0.037 \\
\hline Tuổi & -0.300 & $-0.057^{* *}$ & 0.029 \\
\hline Học vấn & 1.657 & $0.314^{\mathrm{ns}}$ & 0.328 \\
\hline Thành viên & 0.838 & $0.159^{\mathrm{ns}}$ & 0.158 \\
\hline Thu nhập khác & -3.831 & $-0.727^{* * *}$ & 0.237 \\
\hline Số quan sát: 78 & & \\
\hline LR Chi ${ }^{2}=40.00$ & & \\
\hline Prob $>\mathrm{Chi}^{2}=0.0000$ & & \\
\hline Pseudo $\mathrm{R}^{2}=0.7488$ &
\end{tabular}

Ghi chú: ***, ** tương ứng với mức ý nghĩa $1 \%$ và $5 \%$, ${ }^{\mathrm{ns}}$ không có ý nghĩa thống kê

Nguồn: Tính toán từ số liệu khảo sát (2019)

Kết quả phân tích mô hình Logit trong Bảng 10 với Prob $>\mathrm{Chi}^{2}=0.0000$ cho thấy mô hình phân tích có ý nghĩa về mặt thống kê. Kết quả nghiên cứu xác định có 3 yếu tố ảnh hưởng đến quyết định này. Biến diện tích với hệ số của ảnh hưởng biên dương nghĩa là khi diện tích tăng lên 01 đơn vị thì xác suất hộ chuyển sang canh tác theo hướng hữu cơ tăng lên. Hai yếu tố tác động ngược chiều đến quyết định tham gia mô hình hữu cơ gồm tuổi chủ hộ và nguồn thu nhập khác. Với mức ý nghĩa 5\% (không như kỳ vọng ban đầu), những chủ hộ lớn tuổi hơn thường có tâm lý e ngại sự thay đổi, sợ nhiều rủi ro nên thường họ ít có động lực tham gia vào các mô hình mới. Biến thu nhập khác có tác động âm, đúng với giá trị kỳ vọng của nghiên cứu và có mức ý nghĩa thống kê $1 \%$. Như vậy, những hộ có nhiều nguồn thu nhập ngoài trồng lúa thì có xu hướng không muốn chuyển đổi sang mô hình hữu cơ hơn những hộ chỉ có nguồn thu nhập chính từ trồng lúa. Theo kết quả biến thu nhập khác có giá trị tác động biên là âm 0.727 , giá trị này cho biết nếu nông hộ có thêm nguồn thu nhập khác thì xác suất về thực hiện ý định canh tác mô hình hữu cơ nhỏ hơn những nông hộ không có nguồn thu nhập khác ngoài trồng lúa. Hai yếu tố gồm học vấn và số thành viên trong gia đình không có ý nghĩa, điều này chỉ ra việc không có sự khác nhau trong quyết định chuyển đổi mô hình hữu cơ giữa người có học vấn cao và người có học vấn thấp, giữa số thành viên trong gia đình nhiều và số thành viên trong gia đình ít.

\section{Kết luận và hàm ý chính sách}

Từ nội dung phân tích và so sánh tình hình sản xuất và đánh giá các chỉ tiêu tài chính của mô hình truyền thống và theo hướng hữu cơ, một số kết luận quan trọng được tóm lại như sau: mặc dù chi phí của mô hình hữu cơ còn cao so với mô hình truyền thống và năng suất chưa có nhiều khác biệt. Cụ thể chi phí sử dụng phân sinh học cao chiếm gần $50 \%$ trong cơ cấu chi phí, mô hình hữu cơ có lợi nhuận khoảng 1.4 triệu đồng/ $1,000 \mathrm{~m}^{2}$ tương đương mô hình truyền thống 
do giá bán cao và được bao tiêu sản phẩm. Bên cạnh đó, giai đoạn đầu sản xuất theo hướng hữu cơ, nông hộ còn một số trở ngại như về kỹ thuật mới, cách sử dụng phân bón hữu cơ sinh học và nhất là tốn nhiều công chăm sóc hơn làm cho chi phí cao hơn mô hình truyền thống; Ngoài ra, do được liên kết bao tiêu, giá bán cao hơn $25 \%$ so với giá lúa thường mặc dù năng suất chưa bằng mô hình cũ, chính điều này giúp cho doanh thu và lợi nhuận của mô hình hữu cơ rất khả quan về mặt lâu dài; Mô hình phân tích với 07 biến ảnh hưởng đến lợi nhuận chuẩn hóa của mô hình truyền thống, có 02 yếu tố tác động cùng chiều gồm tập huấn và lao động gia đình, trong khi phân và giống tác động ngược chiều dựa trên kết quả ước lượng mang dấu âm, kết quả này là đúng theo kỳ vọng và lý thuyết và đây là tín hiệu tốt cho sự thay đổi sang mô hình mới vì rất giống với đặc điểm canh tác của hình thức theo hướng hữu cơ. Kết quả phân tích các yếu tố ảnh hưởng đến quyết định chuyển đổi sang mô hình hữu cơ chỉ ra yếu tố diện tích làm tăng xác suất việc đồng ý canh tác mô hình mới, trong khi nếu nông hộ có đa dạng hóa thu nhập hoặc chủ hộ lớn tuổi sẽ làm giảm xác suất này. Cụ thể, những chủ hộ lớn tuổi thường có tâm lý e ngại sự thay đổi, do đó họ không đồng ý chuyển sang hình thức canh tác mới. Ngoài ra, các nông hộ có thể đa dạng hóa thu nhập cũng có ít động lực chuyển đổi hơn. Do đó, chính quyền địa phương và các cấp ban ngành có liên quan cần tăng cường tuyên truyền vận động người dân nhận thức rõ lợi ích lâu dài của mô hình này và đây cũng là xu hướng chuyển đổi theo đúng định hướng của Đảng và Nhà nước và nền nông nghiệp 4.0.

Như vậy, nhằm cải thiện hiệu quả tài chính của hình thức canh tác theo hướng hữu cơ và tăng khả năng chuyển đổi sang mô hình mới, các bên liên quan cần quan tâm những giải pháp sau:

Tích cực tuyên truyền phổ biến thông tin về mô hình "lúa hữu cơ" là hình thức có sự liên kết giữa 05 nhà (gồm cả ngân hàng - nhà bank) hướng đến xây dựng vùng nguyên liệu lúa hàng hóa xuất khẩu. Việc chuyển đổi sang mô hình này của hộ sẽ được đảm bảo nguồn giống tốt, cũng như phân bón và thuốc nông dược, hợp tác với doanh nghiệp thu mua lúa và khép kín từ khâu cung ứng đầu vào đến bao tiêu sản phẩm cho thành viên tham gia. Mối liên kết này có phân chia quản lý với cách chức năng cụ thể, cán bộ kỹ thuật sẽ trực tiếp hướng dẫn và nhắc nhở định kỳ tập huấn cho nông hộ. Đặc biệt chủ động trong các khâu giống, phân bón, thuốc nông dược, đặc biệt là tìm thị trường đầu ra ổn định.

Ngoài hiệu quả về mặt tài chính và kinh tế, mô hình trồng lúa hữu cơ được kỳ vọng đạt được hiệu quả về mặt môi trường mà trực tiếp là sức khỏe của người tham gia sản xuất. Chính quyền địa phương cần tổ chức các buổi giao lưu giữa các hộ mô hình cũ với mới để các nông hộ thấy được những hiệu quả và lợi ích mà lúa hữu cơ mang lại. Đối với mô hình hữu cơ hiện tại, chú ý điều chỉnh lượng phân hữu cơ sinh học hợp lý và tập huấn thêm cho người dân quen với các kỹ thuật canh tác, từ đó giảm dần chi phí lao động.

Nhà nước cần ưu tiên thực hiện việc giảm số lượng nhập khẩu các loại thuốc bảo vệ thực vật, từ đó giúp giảm lượng phân vô cơ và thuốc hóa học sử dụng trên đồng rộng. Ngoài ra, các cơ quan ban ngành cũng cần tăng cường tuyên truyền và quản lý chặt chẽ các đại lý cung cấp phân bón thuốc bảo vệ thực vật vì họ là những người thường tư vấn trực tiếp và có tác động đến hành vi sử dụng thuốc và phân của nông dân khi sử dụng trên cây trồng. Ngoài ra, để đẩy mạnh phát triển mô hình hữu cơ, các nhà làm chính sách cần nhanh chóng xây dựng bộ tiêu chí và những tiêu chuẩn thiết thực và phù hợp cho sản phẩm hữu cơ, tăng cường khuyến khích người dân và các doanh nghiệp trong việc sản xuất và tiêu dùng các sản phẩm nông nghiệp hữu cơ, trợ giá ban đầu cho các đơn vị sản xuất kinh doanh phân bón sinh học. Cuối cùng, việc chuyển giao các kết quả nghiên cứu về các chế phẩm sinh học, hữu cơ và tiến hành sản xuất ở quy mô công nghiệp cần được ưu tiên thực hiện trong thời gian tới. 


\section{Tài liệu tham khảo}

Bộ Nông nghiệp và phát triển nông thôn. (2016). Quyết định số 1898/QĐ-BNN-TT ngày 23 tháng 05 năm 2016 về phê duyệt "Đề án tái co" cấu ngành lúa gạo Việt nam đến năm 2020 và tầm nhìn đến nhăm 2030" [Decision 1898/QD-BNN-TT dated 23 May 2016 approving "Project on restructuring Vietnam's rice industry to 2020 and vision to 2030”']. Retrieved January 12, 2020, from https://thuvienphapluat.vn/van-ban/Linh-vuc-khac/Quyet-dinh-1898-QDBNN-TT-de-an-tai-co-cau-nganh-lua-gao-Viet-Nam-2020-tam-nhin-2030-2016313302.aspx

Cổng thông tin điện tử Vĩnh Long. (2018). Báo cáo tóm tắt tình hình thưc hiện kế hoạch phát triển kinh tế - xã họi năm 2018 và Kế hoạch phát triển kinh tế - xã họi năm 2019 [The report summarizes the implementation of the socio-economic development plan in 2018 and the socio-economic development plan in 2019]. Retrieved January 15, 2020, from http://www.mpi.gov.vn/Pages/chuyenmuctin.aspx?idcm=518

Debertin, D. L. (2012). Agricultural production economics. Agricultural economics textbook gallery (2nd ed.). Lexington, Kentucky: Amazon Createspace.

Duong, T. N., \& Nguyen, P. V. (2014). Đánh giá hiệu quả tài chính của hai mô hình sản xuất xoài cát ở tỉnh Đồng Tháp [Evaluation of financial efficiency of two production models of sweet mango in Dong Thap province]. Tạp chí Khoa học Trưòng Đại học Cần Tho, 33(2014), 1-10.

Ha, S. V., \& Duong, T. N. (2014). So sánh hiệu quả tài chính giữa mô hình ứng dụng tiến bộ kỹ thuật và mô hình không ứng dụng tiến bộ kỹ thuật trong sản xuất lúa ở Đồng bằng sông Cửu Long [Comparison of financial efficiency between the model with and without technical application in rice production in the Mekong Delta]. Tạp chí Khoa hoc Truờng Đại hoc Cần Tho, 33(2014), 87-93.

La, D. N. T., \& Mai, N. V. (2015). Phân tích hiệu quả tài chính của hộ sản xuất lúa theo mô hình liên kết với doanh nghiệp ở tỉnh An Giang [Analysis of financial efficiency of rice-producing households in co-opperation with enterprises in An Giang province]. Tạp chí Khoa hoc Trường Đại học Cần Tho, 36(2015), 92-100.

Ngo, T. T. M., \& Truong, L. D. (2015). Phân tích hiệu quả tài chính của mô hình nuôi cá lóc đen và nhận thức của người nuôi ở Đồng bằng sông Cửu Long [Analysis of financial efficiency of Channa striata farming and farmers' perceptions in the Mekong Delta]. Tạp chí Khoa hoc Trưòng Đại hoc Cần Tho', 36(2015), 108-115.

Nguyen, A. T. T., \& Vo, L. T. T. (2017). Phân tích hiệu quả tài chính của nông hộ trồng ớt vùng Đồng bằng sông Cửu Long [Analysis of financial efficiency of chili farmers in the Mekong Delta]. Tạp chí Khoa học Trường Đại học Cần Tho, 48(2017), 87-95.

Nguyen, T. V., Nguyen, T. V., Cao, T. T., Nguyen, T. T., Nguyen, C. X., Le, N. V., \& Le, L. V. (2020). Hiệu quả sản xuất lúa hữu cơ theo hợp đồng ở tỉnh Thừa Thiên Huế: Trường hợp nghiên cứu ở xã Phú Lương [Efficiency of contract organic rice production in Thua Thien Hue province: A case study in Phu Luong commune]. Tạp chí Khoa học Nông nghiệp Việt Nam, 18(8), 553-561.

Vo, L. T. T., \& Nguyen, S. P. (2011). Phân tích chuỗi giá trị lúa gạo vùng ĐBSCL [Analysis of the rice value chain in the Mekong Delta]. Tạp chí Khoa họ, Truòng Đại học Cần Tho; $19 a(2011), 96-108$. 